\title{
Relaciones entre los actores públicos y privado individual del alojamiento turístico en Santa Clara
}

Recibido: 07/03/17· Aceptado: 22/06/17

\author{
Kenia Álvarez Cepero* \\ Roberto Muñoz González \\ Esther Lidia Machado Chaviano \\ Universidad Central Marta Abreu de Las Villas
}

\section{RESUMEN}

El turismo es una actividad multisectorial y depende en gran medida de una relación saludable entre los diferentes componentes de los sectores implicados. La capacidad de desarrollo turístico de un territorio está directamente relacionada con la voluntad de los actores para establecer relaciones entre ellos, implicándose de forma conjunta y coordinada en la mejora de las condiciones del territorio para asumir los retos derivados de estos procesos. Con la aparición en el panorama económico cubano del sector privadoindividual en la actividad de alojamiento y su desarrollo dinámico en el contexto de las nuevas políticas económicas del país, se hace necesario analizar científicamente las relaciones que se producen entre este y el sector estatal a partir de un procedimiento de diagnóstico relacional. Los resultados obtenidos muestran las características e insuficiencias de las relaciones de cooperación entre los actores estatales y privados del alojamiento turístico -condición que limita la participación de estos en los diversos mecanismos de desarrollo turístico del municipio de Santa Clara-, y dotan al gobierno local de información válida para establecer estrategias de cooperación entre ambos sectores a partir de la conformación de redes turísticas territoriales.

Palabras clave: Relaciones estatal-privado, alojamiento turístico, desarrollo territorial.

*Correos electrónicos: keniaac@uclv.edu.cu·rmuñoz@uclv.edu.cu·esthermc@uclv.edu.cu

Teoría y PraXis · ISSN 18701582 · nÚM. 23 · SEPTIEMBRE-DiCIEMBRE 2017 · pp. 71-91 


\title{
Relations between public and private individual actors in tourism accomodations in Santa Clara
}

Recieved: 07/03/17 - Accepted: 22/06/17

\author{
Kenia Álvarez Cepero* \\ Roberto Muñoz González \\ Esther Lidia Machado Chaviano \\ Universidad Central Marta Abreu de Las Villas
}

\begin{abstract}
Tourism is a multisectoral activity and to a large extent depends on a healthy relationship between the different components of the sectors involved. The capacity of tourism development of a territory is directly related to the will of the actors to establish relations between themselves, being involved in a joint and coordinated way in the improvement of the conditions of the territory to assume the challenges derived from these processes. With the emergence of the private-individual sector in the economic activity of Cuba and its dynamic development in the context of the new economic policies of the country, it is necessary to scientifically analyze the relations that occur between them and the state through a relational diagnostic procedure. The results obtained show the characteristics and inadequacies of the cooperation relations between the state and private actors of the tourist accommodation; a condition that limits the participation of these actors in the various mechanisms of tourism development in the municipality of Santa Clara and provide the local government with valid information to establish strategies for cooperation between both sectors based on the conformation of networks of territorial tourism.
\end{abstract}

KEY WORDs: State-private relations, tourist accommodation, territorial development.

*E-mails: keniaac@uclv.edu.cu·rmuñoz@uclv.edu.cu·esthermc@uclv.edu.cu 


\section{Introducción}

En el turismo se destacan cuatro actores que poseen una gran capacidad para influir y configurar el territorio: la comunidad local, el sector público, el sector privado y los turistas. Estos últimos no forman parte del territorio configurado como destino, sin embargo, el poder de apropiación simbólica que ejercen en ese espacio es significativa (Velasco, 2016).

La capacidad de desarrollo turístico de un territorio está directamente vinculada con la voluntad de los actores para establecer relaciones entre ellos, implicándose de forma conjunta y coordinada en la mejora de las condiciones del territorio para asumir los retos derivados de estos procesos.

El alojamiento se ha transformado de muchas y variadas maneras a través del tiempo, empero, el servicio fundamental es satisfacer las necesidades del viajero, el cual requiere dormir en determinado lugar. Independientemente de la historia que hayan tenido los servicios hoteleros, el alojamiento turístico, según la normativa comunitaria, se define como cualquier estructura empresarial que presta un servicio de alojamiento de forma regular (Organización Mundial del Turismo, 2001).

En el caso de Cuba, las directrices para la actualización del modelo económico plantean, por una parte, que el

modelo de gestión reconoce y promueve, además de la empresa estatal socialista, que es la forma principal en la economía nacional, las modalidades de inversión extranjera previstas en la ley (empresas mixtas, contratos de asociación económica internacional, entre otras), las cooperativas, los agricultores pequeños, los usufructuarios, los arrendatarios, los trabajadores por cuenta propia y otras formas, todas las que, en conjunto, deben contribuir a elevar la eficiencia. ${ }^{1}$

Por otra parte, en alusión al peso de la actividad no estatal en el sector del turismo, se expresa que la "actividad no estatal en alojamiento, gastronomía y otros servicios, se continuará desarrollando como oferta turística complementaria a la estatal". ${ }^{2}$

${ }^{1}$ Esta es la letra del Lineamiento 02 correspondiente a los Lineamientos Generales del Módulo I Modelo de Gestión Económica, aprobados como Política Económica y Social del Partido y la Revolución en el VI Congreso del Partido Comunista de Cuba en abril de 2011.

${ }^{2}$ Lineamiento 262 correspondiente a la Política del Turismo (Partido Comunista de Cuba, 2011). 
Ante la nueva realidad del país, surge la apremiante necesidad de estudiar la adopción de estrategias incluyentes e integradoras, basadas en la premisa de la búsqueda de relaciones de concertación y cooperación para una mejor gestión del turismo. Es decir, se considera pertinente proponer desde la ciencia una serie de mecanismos en concordancia con los principios de políticas económico-sociales que establece el país, mediante las cuales se estimule la inclusión creativa del sector privado-individual como parte de la oferta cooperada de prestadores de servicios turísticos, a través de acciones progresivas de fortalecimiento empresarial, promoción turística, mejoramiento de las infraestructuras, adopción de buenas prácticas y aporte a la competitividad del turismo en los territorios, bajo criterios óptimos de calidad y sostenibilidad.

En Cuba, la creciente oferta de alojamiento privado-individual en los principales destinos turísticos nacionales origina un incremento de la calidad y la sostenibilidad de los productos turísticos tradicionales. Por tanto, los municipios cubanos no están exentos de la necesidad de conocer las relaciones entre los sectores estatal y privado-individual de alojamiento, por lo que se torna indispensable adoptar instrumentos que permitan diagnosticar la situación actual de las relaciones entre ambas partes.

De este modo, conocer las mejores condiciones de las relaciones entre actores de dos dimensiones que, hasta el momento, se analizan como contrapuestas y muchas veces incompatibles en un territorio, comienza a concitar cada vez más la atención de gobiernos locales, académicos, gestores de la actividad turística y todos aquellos preocupados por entender las variables que determinan el bienestar de una sociedad.

Sin embargo, manifestándose interés y disposición, la principal limitación consiste en el desconocimiento de los niveles de relaciones existentes entre los sectores estatal y privado-individual correspondientes al alojamiento del municipio de Santa Clara, lo que evidencia como objetivo de esta investigación el análisis de las relaciones entre los sectores de la actividad de alojamiento turístico en el municipio, de manera que esta información constituya el cimiento para proponer estrategias en función de su aprovechamiento y contribución al desarrollo local.

Este trabajo se justifica tanto en el plano teórico como en el práctico, dado que se pretende valorar el papel que tiene y debe tener dentro la estructura 
socioeconómica del municipio estudiado el sector privado-individual de alojamiento turístico como forma de gestión de la economía no estatal. Se intenta demostrar su estructura, sus dinámicas de gestión, así como la importancia de los principales impactos generados por tal actividad en el proceso de consolidación del destino turístico local y, por tanto, en su capacidad para contribuir de manera virtuosa al desarrollo socioeconómico del municipio.

\section{Antecedentes}

El estudio de las relaciones de los actores en el turismo -geometrías de poder o dinámicas relacionales, como denominan Rodríguez y Fernández (2009) y Massey (2009)- constituye un factor explicativo sobre la configuración y asentamiento de la actividad en un territorio, la transformación de ese territorio bajo distintas concepciones, y la creación y surgimiento de un modelo de desarrollo turístico. Vinculado con esta idea de transformación social surge el término gobernanza, concepto complejo que agrupa diferentes teorías y prácticas cuyo único punto en común es la preocupación por entender que junto a las formas clásicas de organización social -el mercado para la esfera privada y la jerarquía para el ámbito público- aparecen otras en las que la cooperación y la colaboración son la clave (Bevir, 2011).

Por ello, desde la Organización Mundial del Turismo (2001) se ha venido defendiendo que la colaboración entre los actores locales públicos y privados es un elemento cardinal para articular el desarrollo turístico de un determinado territorio.

En términos turísticos, "la capacidad de desarrollo de un territorio está directamente relacionada con la voluntad de los actores para establecer relaciones entre ellos, implicándose de forma conjunta y coordinada en la mejora de las condiciones del territorio” (Rodríguez y Fernández, 2009, p. 174). En otras palabras, existe una relación directa entre la forma de relaciones entre los actores vinculados en la actividad y el modelo y nivel de desarrollo turístico que se alcanza.

Dadas las nuevas tendencias en la actividad turística, así como las nuevas perspectivas locales en pos del desarrollo de los territorios, se hace cada vez más imprescindible mantener estrechos lazos de relación entre ellos, para certificar una apropiada gestión de las ofertas de alojamiento turístico en los espacios 
receptores y, por ende, un incremento del desarrollo económico territorial, sobre las bases de relaciones de cooperación y colaboración.

Para organizarse de manera efectiva y eficaz resulta fundamental que los roles de cada actor estén claros y que haya consenso sobre ellos. El reparto de funciones entre los sectores privado y público dependerá del modelo de administración pública de cada destino pero, en general, existe una tendencia creciente a conceder mayor protagonismo al sector privado.

La realidad económica, política y social de Cuba demanda conocer las relaciones entre los sectores público y privado-individual de la actividad de alojamiento en territorios donde la oferta de este último es mayor que la estatal, por lo que deviene cardinal valerse de instrumentos que permitan diagnosticar la situación actual de las relaciones entre ambas partes. Desde 1993 se desarrollan legalmente actividades de turismo no estatal como la de alojamiento, y más tarde se autorizó la apertura de los denominados paladares, instalaciones que pudieran clasificarse como de restauración gastronómica turística.

Por otra parte, el Acuerdo CM-43/11 del Consejo de Ministros, que aprueba la actualización de la proyección de la economía hasta 2016, puntualiza: “El Mintur [Ministerio de Turismo] deberá considerar en su proyección económica, la incidencia del incremento de la participación del sector privado en el turismo, ya que no es despreciable la cifra que pueda alcanzarse y como rector de la actividad turística en el país, debe conducir este proceso para que no nos sorprenda”.

Al cierre de 2016 existen en el país 1600 paladares $^{3}$ y más de 8000 habitaciones que prestan servicios de alojamiento, dirigidas fundamentalmente al turismo internacional y también al mercado interno pagando en pesos cubanos convertibles (Cuc). Ese número equivale a $13 \%$ de las 60000 habitaciones que conforman la capacidad hotelera total que opera el Estado (Marrero, 2016).

Algunos territorios cubanos, principalmente con vocación turística histórico-cultural, han tenido un gran dinamismo en el incremento de las actividades del sector privado-individual; en especial es significativo el crecimiento sinérgico de los alojamientos privados. Ante este escenario, la participación activa de la oferta privado-individual deberá jugar un rol protagónico en la relación entre la oferta y la demanda. Esta participación activa se justifica por la necesidad de

${ }^{3}$ Llámese en Cuba a los establecimientos restauración pertenecientes al sector privado-individual. 
garantizar espacios de alojamiento, restauración, ocio y recreación que satisfagan las demandas de crecientes flujos de visitantes con motivaciones diferentes del turismo de playa, y que el sector estatal -por tiempo y recursos- asume con dificultades (Perelló, 2015).

La realidad del modelo cubano aún no viabiliza los procedimientos para dotar de mayor autoridad y poder de decisión a los gobiernos locales. Todo sistema de desarrollo que incluye turismo conlleva consenso, coordinación y cooperación, donde el mejor indicador de su vialidad lo constituye el grado de compromiso de todos los agentes implicados, directa o indirectamente, y, por supuesto, la población residente.

Resulta de gran interés por parte de los gobiernos locales y de otros actores interesados en el progreso del destino turístico el hecho de desarrollar ofertas de alojamiento novedosas, principalmente privadas, que gocen de mucha aceptación por los visitantes dado el nivel de especialización que presentan y su acercamiento a la realidad cubana, así como lograr una relación bilateral con las entidades de alojamiento públicas.

El desafío de la cooperación público-privada que enfrentan los modernos gobiernos municipales se manifiesta en tres niveles:

1. Desde el punto de vista ideológico implica romper con prejuicios que oponen lo público a lo privado: como fundamento del sistema político social se defiende la forma de propiedad y gestión estatal como la base de nuestra economía pero se empiezan a dar pasos para el reconocimiento de la propiedad privada a escala individual a través de la figura del trabajador por cuenta propia (ТСP) y las cooperativas no agropecuarias.

2. Desde el punto de vista legal, el desafío está dado por una actualización del marco normativo, que permita e incluso facilite los emprendimientos conjuntos municipio-empresa.

3. Desde el punto de vista instrumental, la cuestión radica en la forma concreta en que estas dos lógicas y modus operandi pueden vincularse, con resultados fructíferos. Justamente, lo que se busca con la cooperación público-privada es trabajar en conjunto, aproximando visiones y optimizando recursos. Ello implica necesariamente un proceso de conocimiento y aprendizaje mutuo, que se ve estimulado si ambas partes perciben que la cooperación es beneficiosa. 


\section{Metodología}

Las relaciones intersectoriales en el turismo como línea de investigación forma parte de un campo científico más amplio al que podemos denominar perspectiva relacional, caracterizado por utilizar la idea de relaciones como un elemento de gran importancia para comprender el fenómeno turístico.

La literatura especializada propone además numerosos procedimientos para desarrollar sistemas de gestión integrada en los destinos turísticos (Oyarzún y Szmulewicz, s. f.; Müffeler, 2006; Mondéjar et al., 2009; Betancourt, Falcón y García, 2010; y Machado, 2012). Los autores de estos procedimientos coinciden en la identificación de las partes interesadas en el desarrollo del destino turístico y en la definición de estrategias y acciones a poner en marcha por cada una de estas partes en la articulación del sistema.

A partir de esta información se destacan dos ideas esenciales: la primera es que las relaciones como elemento explicativo del turismo han tenido un amplio e importante uso en la investigación existente en la literatura científica; y la segunda consiste en que los trabajos encontrados en esa literatura científica que aplican el análisis de relaciones intersectoriales para el estudio del fenómeno turístico han sido bastante escasos (Merinero, 2015).

La mayoría de las metodologías que se plantean en los estudios evaluados se basa en herramientas de las ciencias sociales ideales para investigaciones cualitativas, explicativas y no experimentales. En esta investigación, la metodología empleada se fundamentó en la realización de entrevistas en profundidad a actores estatales y privados de la actividad de alojamiento turístico, teniendo en cuenta los casos de personas con liderazgo y capacidad para generar opinión respecto a la actividad turística; finalmente, se interpretaron los resultados triangulando la información entre los grupos estudiados, reforzando con los datos cuantitativos obtenidos mediante los cuestionarios.

Para obtener la información relacional necesaria en este procedimiento fue imprescindible atender a las características de esos actores turísticos. De esta forma, se consideran como tales administraciones públicas locales, hoteles, habitaciones del sector privado-individual, e instituciones del territorio y representantes de la sociedad civil cuya actividad afecta directamente al turismo del territorio, así como el análisis de documentos que informan sobre las actividades turísticas que se desarrollan. 
Como resultado, el procedimiento planteado facilitaría las estrategias necesarias a futuro para establecer tal estructura relacional orientándose la propuesta del lado de la determinación de principios necesarios para la gestión de relaciones entre actores del alojamiento turístico y cuyo liderazgo del proceso será del lado de los actores públicos y, por tanto, la estrategia de cooperación se centrará en el campo de la administración del turismo en el territorio.

La propuesta de la autora consta de cinco etapas y once tareas. Cada etapa comprende objetivos a desarrollar, y las tareas definen cómo desarrollar en cada etapa los objetivos trazados. De acuerdo con los objetivos de este trabajo,

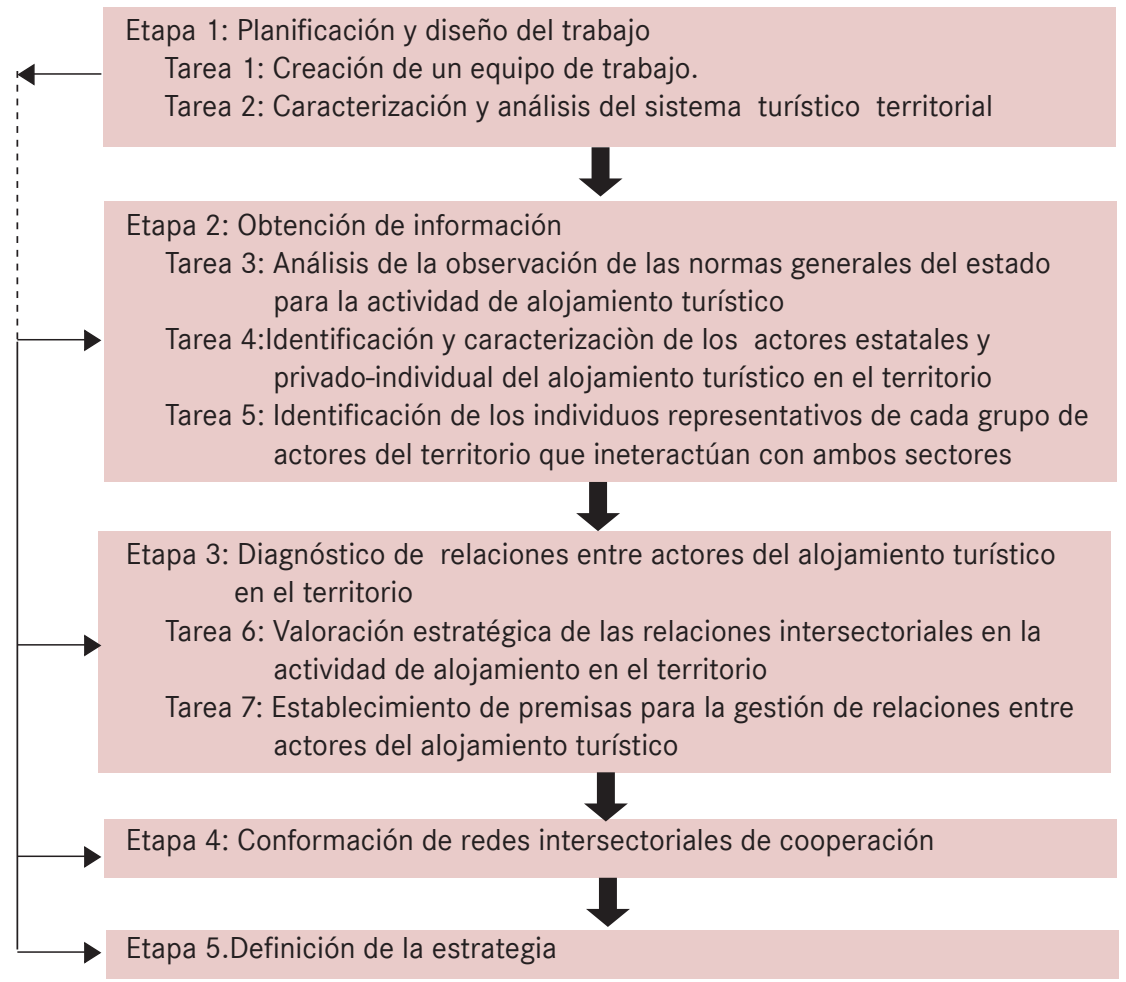

Fuente: Elaboracion propia.

Figura 1. Procedimiento para la definición de estrategias de cooperación integrada entre los actores de alojamiento turístico en un territorio 
se aplicaron únicamente las tres primeras etapas del procedimiento para la definición de estrategias de cooperación integrada entre los actores de alojamiento turístico en un territorio, aportado por la autora, correspondientes a la creación del equipo de diagnóstico, la obtención de información, y el diagnóstico de las relaciones entre los sectores estatal y privado-individual del alojamiento turístico en un territorio.

El procedimiento propuesto se basa en las nuevas formas de gestión económicas en Cuba, en las características de la sociedad cubana y en el área de acción en la que se analizan las relaciones de los sectores, en este caso el alojamiento, aunque esto no significa que no sea adaptable a otras áreas como la restauración, el transporte o la recreación.

\section{Resultados del estudio del municipio de Santa Clara}

El municipio de Santa Clara ha tenido un dinamismo en el incremento de las actividades del llamado sector no estatal, pero en especial es significativo el crecimiento acelerado de las habitaciones para el alojamiento turístico (más de 150 habitaciones en 2016) como forma de negocio privado-individual. No obstante, se advierte la necesidad de establecer mecanismos de cooperación más estrechos entre las instituciones y organizaciones del Estado responsables de la industria turística, y el sector privado-individual, particularmente en cuanto a infraestructura y servicios de alojamiento, lo que no niega otros posibles ámbitos como transporte, insumos, etc. Todo ello debe contribuir no solo a una mejor gestión del municipio, sino a la vez a su desarrollo socioeconómico virtuoso y de su entorno.

Para realizar el diagnóstico se conformó un equipo de trabajo compuesto por siete miembros, entre ellos especialistas de alto prestigio y representativos de:

1. Consejo de la Administración Territorial.

2. Directivos de organismos del sector estatal que participan del proceso de relacionamiento.

3. Directivos de empresas estatales prestatarias de servicios de alojamiento turísticos del territorio.

4. Propietarios del sector privado-individual del alojamiento en el territorio

5. Investigadores de los centros de investigación y enseñanza. 


\section{Caracterización y análisis del sistema turístico territorial}

Santa Clara es la capital de la provincia cubana de Villa Clara. Limita al noreste con Cifuentes, al noroeste con Camajuaní, al este con Placetas, al sureste con Manicaragua y al suroeste con Ranchuelo.

Tiene una población estimada de 220000 habitantes, que en su mayoría radica en la ciudad principal y cuenta con alrededor de 67300 viviendas. Demográficamente está catalogada como ciudad urbana y es aquella con más esperanza de vida del país (arriba de 75 años), producto de su paulatino envejecimiento poblacional (Oficina Nacional de Estadísticas, 2016).

Las características económico-sociales de la localidad tienen sus bases en la industria. Posee gran capacidad de producción instalada con tres zonas industriales y 163 instalaciones de producción, así como un fuerte polo científico y biotecnológico con cinco instalaciones de tecnologías de punta. Es sede de grandes instalaciones de servicios provinciales regionales en sectores como la salud, la cultura y la educación.

Constituye un complemento turístico de significativa importancia para el destino Cayos de Villa Clara, situado al norte de la provincia, debido a la cantidad de atractivos turísticos presentes en el municipio, principalmente los histórico-culturales y arquitectónicos. Sin embargo, la ciudad cuenta con una infraestructura hotelera y extrahotelera insuficiente destinada a la modalidad de turismo de ciudad y cultural.

Su oferta turística comprende diversas actividades, como alojamiento, restauración, ocio y recreación, transportación, y otros servicios de apoyo al turismo. En cuanto al alojamiento, existen hasta la fecha 285 viviendas turísticas operando en moneda convertible (CUc), 85 más que en igual fecha de 2016; y cuatro hoteles, tres de los cuales operan con la marca Cubanacán (Los Caneyes, Villa la Granjita y América) y uno con la cadena Islazul (Santa Clara Libre) (Mintur, 2016).

Para el servicio de restauración, la ciudad de Santa Clara cuenta con 19 instituciones perteneciente al Grupo Empresarial Extrahotelero Palmares Sucursal Villa Clara. Existen varias instalaciones que tienen espacio para actividades culturales en su microentorno. Además, el sector no estatal se ha manifestado con un paso creciente en la restauración del destino (Oficina Nacional de Administración Tributaria, 2016). 
Respecto al ocio y la recreación, hay en la ciudad dos centros nocturnos, cinco cabarets, dos salas de fiesta, un bar club y otras cinco instalaciones que por el servicio que brindan son netamente recreativas.

En cuanto a la transportación turística, se encuentra en el territorio la Sucursal Transtur Villa Clara, subordinada al Grupo Empresarial Transtur S. A., que comercializa servicios de transporte turístico en las modalidades de ómnibus y renta de autos. La ciudad tiene un aeropuerto internacional, con una localización adecuada al noreste de la misma a una distancia de $11 \mathrm{~km}$ a partir de la circunvalación. El municipio cuenta con dos estaciones ferroviarias, Santa Clara y Cenizas, un centro de carga y descarga de mercancías, así como un taller de mantenimiento y revisión técnica de las locomotoras y vagones.

En la ciudad también se ubican varias instalaciones de apoyo al turismo: cuatro agencias de viaje (AAvv Cubanacan, AAvv Cubatur, Aavv Havanatur y AAVV Gaviotatur), siete tiendas (Caracol) y una oficina de información turística (Infotur).

Con relación a la demanda turística, se tiene lo siguiente:

- Forma de viaje: de acuerdo con las encuestas de salida del destino Villa Clara realizadas por Infotur en diciembre de 2015, se pudo constatar que los visitantes al municipio organizan su viaje tanto de forma individual como mediante agencias de viajes, según muestra la figura 2.

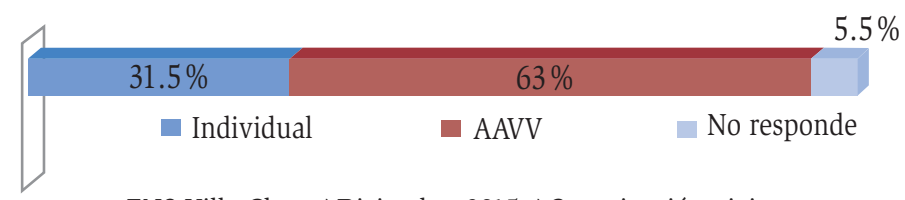

ENS Villa Clara / Diciembre 2015 / Organización viaje

Fuente: ENS Villa Clara.

Figura 2. Formas de organización de viaje diciembre de 2016

- Origen de la demanda: los viajeros que visitan Santa Clara provienen en su mayoría de Canadá, principal mercado emisor de clientes, y el segundo lo constituye Estados Unidos. Le siguen mercados como Polonia, Alemania, Argentina, Italia y Francia (Mintur, 2016). 
- Motivo de viaje: el móvil principal de quienes eligen visitar Santa Clara está determinado fundamentalmente por el pueblo, la cultura y el patrimonio, así como por cuestiones de seguridad. En este aspecto es relevante la influencia que tiene la figura del Che Guevara en el mundo.

- Estancia promedio: el turismo que se desarrolla es mayormente de tránsito, y se encuentra en el rango de entre 1.6 y 1.8 días en hoteles; aunque resulta notable la estancia promedio en viviendas turísticas particulares, la cual es de aproximadamente 2.4 días (Mintur, 2016).

El municipio presenta un potencial turístico medio (Moya, 2015), sobresaliendo los indicadores turísticos y los antrópicos, en especial el equipamiento y los servicios disponibles, además de la receptividad y las cualidades humanas de la población local. Los indicadores ambientales y de percepción son los más desfavorables.

\section{Análisis de la observación de las normas generales del Estado para la actividad de alojamiento turístico}

Las normas que rigen en Cuba los establecimientos de alojamiento turístico solo comprenden a entidades del sector público y no del privado-individual. Para la actividad de alojamiento turístico estatal se dispone de una serie de regulaciones legales que establece, entre otros, los Requisitos mínimos para los Establecimientos hoteleros (NC127:2014), pero en ellas no aparece contemplado el sector privado-individual.

Dentro del marco legal que ampara la actividad de alojamiento turístico privado-individual se encuentran la Ley No. 65 de 1988 Ley General de la Vivienda, el Decreto-Ley No. 275 de 2010 Modificativo del régimen de arrendamiento de viviendas, habitaciones o espacios, y la Resolución No. 305/2010 Reglamento sobre el arrendamiento de viviendas, habitaciones y espacios, del Instituto Nacional de la Vivienda.

Además se relacionan:

- La Resolución No. 298/2011 del Ministerio de Finanzas y Precios, que regula lo relacionado con el impuesto sobre los servicios públicos (ISSP) en lo concerniente al arrendamiento de viviendas, habitaciones o espacios.

- El Decreto Ley 305 de 2012, soporte jurídico que aprueba las cooperativas no agropecuarias. 
- La Resolución No. 32 de 2013 del Ministerio de Economía y Planificación, que amplía las posibilidades de vínculos comerciales entre los sectores no estatal (privado) y estatal.

De manera general, se observa una falta de convergencia jurídica en la actividad turística que permita a través de alguna fórmula legal o institucional la presencia en instrumentos legales de los intereses públicos y privados en función del desarrollo turístico.

\section{Identificación y caracterización de los actores estatales y privado-individuales del alojamiento turístico en el territorio}

Los actores estatales son todos aquellos hoteles que se encuentran en la ciudad cuya administración y dirección corre a cargo del Estado. Para obtener información se tuvieron en cuenta las opiniones de los directivos de cada uno de estos hoteles, en representación del sector público.

Actualmente existen cuatro hoteles, los cuales operan con dos cadenas hoteleras, que en conjunto tienen alrededor de 359 habitaciones, como se observa en el cuadro 1.

Cuadro 1. Habitaciones del sector estatal en el municipio de Santa Clara

\begin{tabular}{lllc}
\multicolumn{1}{c}{ Hotel } & \multicolumn{1}{c}{ Cadena } & \multicolumn{1}{c}{ Categoría } & Habitaciones \\
Santa Clara Libre & Islazul & 2 Estrellas & 165 \\
Los Caneyes & Cubanacán & 3 Estrellas & 96 \\
La Granjita & Cubanacán & 3 Estrellas & 71 \\
América & Cubanacán & 3 estrellas & 27
\end{tabular}

Fuente: Elaboración propia a partir del Mintur (2016).

Asimismo, hay un plan de desarrollo para aumentar la planta habitacional del municipio de Santa Clara en más de 200 habitaciones, hasta el 2030.

Del análisis de la situación actual de alojamiento en Santa Clara del sector estatal, se puede decir que los principales impactos y contribuciones económicos al desarrollo local son:

- Se amplía la proyección del horizonte temporal del desarrollo del turismo y se adecuan las estructuras organizativas a los ritmos de desarrollo. 
- Interés por recuperar y hacer crecer la planta hotelera.

- Las entidades públicas representan, además de los intereses estatales, los de la población anfitriona.

- Se diseña y concreta la comercialización más eficiente del destino turístico, incluyendo la diversidad de productos turísticos.

Los actores privado-individuales del alojamiento turístico están constituidos por las viviendas arrendadas con fines turísticos en la localidad, así como su número de habitaciones. Se evidencia la existencia de subdeclaración como mecanismo de evasión fiscal y de alrededor de 625 habitaciones en uso, a pesar de no estar declaradas legalmente 235 de ellas. Estos datos revelan la capacidad habitacional que presenta el sector privado-individual, la cual supera al estatal en aproximadamente 266 habitaciones.

Los resultados muestran que $44 \%$ de los encuestados son mujeres y $56 \%$ hombres, observándose así cierto equilibrio en la realización de la actividad.

En un rango de entre 24 y 80 años, la edad promedio de los propietarios de los negocios es de 54 años. De ellos, $52.6 \%$ tiene nivel superior de escolaridad, mientras que 35, 11.7 y $0.7 \%$ cuentan con niveles técnico medio, preuniversitario y primario, respectivamente. La procedencia ocupacional de la mayoría es jubilados, ex trabajadores estatales, amas de casa y desvinculados.

En promedio, el tiempo que los propietarios llevan ejerciendo esta actividad es de cuatro años y medio, oscilando entre uno y diez años de ejercicio.

Respecto a la fuente de financiamiento para dar inicio al negocio, 82 propietarios declararon que fue por remesas familiares, 39 por ahorro bancario, 11 por ingresos debido a misiones en el extranjero, 12 por créditos del banco y 28 por otras fuentes de financiamiento, como el ahorro personal y los préstamos provenientes de un pequeño grupo de personas que actúan como usureros informales, con capitales suficientes como para financiar distintas actividades. Estos capitales acumulados durante varios años y normalmente en manos de sus dueños y no en las bóvedas de la banca cubana, con frecuencia tienen orígenes dudosos.

Las principales aportaciones del sector privado-individual al desarrollo local del municipio son las siguientes: 
- Ofrece la creación de nuevas capacidades de hospedaje, y con ello aumenta el número de empleos económicamente atractivos.

- Se ha desarrollado una cultura turística en el sector de alojamiento debido a la superación individual del personal asociado con la explotación de esa actividad.

- Contribuye a reducir los gastos de logística del sector estatal y proporciona oportunidades de desarrollo profesional sin la necesidad de la migración, logrando un impacto positivo en la mitigación de la marginalidad de la sociedad.

- Constituye importantes espacios para poner en práctica y desarrollar habilidades creativas e intelectuales, en particular las relativas a la administración e innovación.

\section{Identificación de los individuos representativos de cada grupo de actores del territorio que interactúan con ambos sectores}

Varias instituciones, empresas e individuos que constituyen un complemento para la actividad de alojamiento, y que representan los intereses estatales, tienen un papel importante en cuanto a regulación, planificación y organización. Los individuos representativos son:

- Delegación territorial del Mintur: organismo estatal rector del Sistema de Turismo.

- Agencias de viajes (AAVv): participan en la intermediación del producto turístico de ambos sectores. Son un punto clave en el desarrollo de las relaciones entre ambos sectores del alojamiento.

- Oficina de Patrimonio: su relación con la actividad de alojamiento tiene que ver con el hecho de que muchas de las viviendas turísticas forman parte del patrimonio local, ya sea por su valor arquitectónico o histórico.

- Oficina Nacional de Administración Tributaria: gestiona y controla el cumplimiento de las obligaciones arancelarias que correspondan a los sujetos obligados con ellas; dentro de estos sujetos se encuentran ambos sectores.

- Planificación Física: institución estatal encargada de velar por la política establecida por el Estado en materia de ordenamiento territorial y urbanismo. 
- Infotur: tiene como objetivo ofrecer información turística gratuita a los visitantes sobre el destino, a través de catálogos, folletos, brochures, etcétera.

\section{Características de relaciones entre actores del alojamiento turístico en el territorio}

Tipos de relaciones. Las relaciones entre el sector público y el privado-individual pueden ser de cooperación, colaboración, asociatividad e integración y tienden a centrarse en cinco áreas principales:

- Comercialización y marketing

- Aprovisionamiento de materias primas, materiales y tecnologías

- Financieras

- Complementación en la gestión turística del territorio

- Ordenamiento territorial y la planificación del desarrollo turístico

De los encuestados del sector privado-individual, $17.5 \%$ mantiene vínculos de cooperación en materia de comercialización con el Estado, solo a través de las agencias de viajes Havanatur, Cubanacán y Cubatur; $4.4 \%$ con el sector mixto, y 69.3 \% con otras viviendas turísticas y negocios privados generalmente. Ante la sugerencia de una posibilidad de asociatividad de las entidades no estatales del alojamiento, $79.4 \%$ de los encuestados está de acuerdo en integrarse en cooperativas, mientras que $70.9 \%$ está dispuesto a crear micros, pequeñas y medianas empresas del alojamiento no estatal, siempre y cuando se les dé un tratamiento diferente de las condiciones actuales -donde solo se emplean cuando las capacidades del sector estatal no satisfacen las demandas, además de que no existen compromisos concretos con su gestión-, por ejemplo, que se les brinden beneficios asociados con la promoción, la información del destino y los suministros de las materias primas e insumos necesarios para el desarrollo de la actividad.

Importancia de las relaciones. A pesar de que la mayoría de los actores considera que la colaboración entre ellos es relevante, esto aún no se ha podido plasmar en la realidad. La importancia de la colaboración es asociada por 78 \% con las contribuciones de las casas particulares al desarrollo local, sobre todo por el 
hecho de que generan empleos económicamente atractivos, ofrecen la creación de nuevas capacidades de hospedaje, y brindan oportunidades de desarrollo profesional sin necesidad de migrar. En tanto, $6 \%$, que refiere la colaboración como medianamente importante, se basa en el argumento de que las fuentes de financiamiento del sector privado-individual presentan un carácter no legal, por lo que pudieran degradarse los valores de nuestras instituciones públicas, además de que constituyen en la actualidad competencia efectiva para la política de créditos dirigida a los trabajadores por cuenta propia que implementa la banca cubana y una fuerte competencia para las entidades estatales.

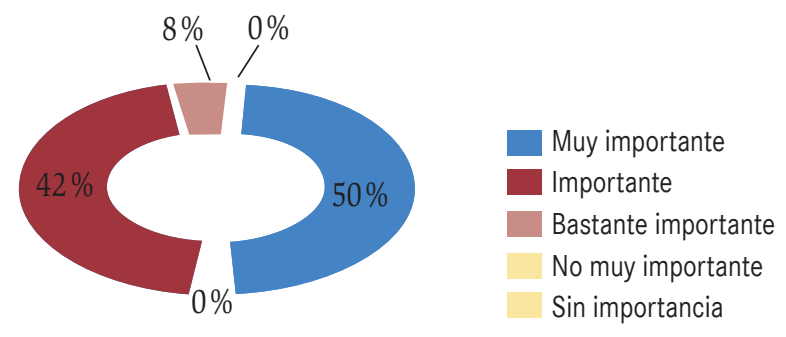

Fuente: Elaboración propia a partir del Mintur (2016).

Figura 3. Importancia de las relaciones

Nivel de relaciones. De los actores encuestados, 69 \% señala que no existe colaboración entre los actores públicos y privados del sector turismo en el destino Santa Clara; esto se debe a que la mayoría argumenta que las relaciones público-privadas se encuentran en fase de organización y desarrollo. Además, se reconoce la ausencia de mecanismos de gobierno que integren los intereses de ambos sectores en función del desarrollo turístico del municipio.

Características de las relaciones. Se obtuvo información mediante el cuestionario que después se profundizó en las entrevistas transcritas y analizadas rigurosamente, para mostrar información relevante de acuerdo con el problema de investigación. En la tercera pregunta del cuestionario se establecieron varias alternativas, dando la oportunidad de marcar más de una, así como de agregar posibles características no mencionadas. El resultado se muestra en el cuadro 2. 
CuAdro 2. Resultados de la evaluación de características de las relaciones

\begin{tabular}{lc}
\multicolumn{1}{c}{ Alternativa } & Respuestas (\%) \\
\hline Desorganización & 90.5 \\
Falta de interés & 58.0 \\
Desconocimiento & 89.6 \\
Informalidad & 79.3 \\
Otros & 49.8 \\
\hline
\end{tabular}

Fuente: Elaboración propia.

CuAdro 3. Características de las relaciones desde la perspectiva de cada actor del alojamiento turístico

$\begin{array}{cc}\text { Característica } & \begin{array}{c}\text { Perspectiva de los } \\ \text { actores públicos }\end{array} \\ & \begin{array}{c}\text { Perspectiva de los } \\ \text { actores privados } \\ \text { individuales }\end{array}\end{array}$

Desorganización Existe una necesidad de trabajar conjuntamente entre los actores, sin embargo predomina la desorganización, la falta de cooperación y la desarticulación.

$\begin{array}{ll}\text { Informalidad } & \text { La informalidad de los negocios } \\ \text { privados del alojamiento es un } & \text { competencia desigual y daña } \\ & \text { problema grave, ya que algunos la imagen del destino. } \\ & \text { realizan su actividad violando } \\ & \text { las normas establecidas. }\end{array}$

Ineficiente gestión El gobierno no desempeña No se sienten respaldados del gobierno un papel protagónico en el ni representados por el fomento y organización de las gobierno. relaciones.

El gobierno del territorio tiene un deficiente poder de gestión.

Desconocimiento Muy pocos actores conocen realmente lo referido a las relaciones, para muchos es algo totalmente nuevo.

Falta de interés en Los representantes del colaborar sector privado individual han decidido emprender sus negocios de forma aislada y velar solamente por sus intereses económicos y personales.
Se sienten desanimados ante las actividades estatales. 
Los diversos actores del alojamiento en Santa Clara consideran que la principal característica de las relaciones entre los actores es la desorganización; 90.5 \% de los encuestados seleccionó esta alternativa, mientras que la informalidad y la desconfianza también son rasgos importantes con 79.3 y $89.6 \%$, respectivamente. Por su parte, $58 \%$ señaló la falta de interés como una característica de la escasa colaboración, y 49.8 \% agregó los siguientes enunciados: falta de información, desconfianza de la importancia turística, burocracia, y falta de profesionales responsables en los cargos públicos.

A partir del criterio de los individuos representativos de los actores del territorio identificados que interactúan con ambos sectores se analizaron los diferentes ámbitos de interrelación:

- Institucional: relacionados con el modelo económico cubano, formas de propiedad y papel del gobierno local en función de la ejecución de funciones en ese sentido.

- Planificación territorial sostenible y conservación patrimonial.

- Productivo: desarrollo de programas para la prestación de servicios locales bajo estándares de calidad.

- Aspectos legales: asesoría para la formalización de relaciones a través de políticas públicas.

- Innovación y transferencia tecnológica.

- Formación y empleo.

Resultaron 24 problemáticas mayormente en los ámbitos institucional (7) y productivo (5), lo cual reafirma la deficiente gestión de gobierno territorial en función de la cooperación entre los sectores público y privado-individual de alojamiento turístico del municipio y su correspondencia y aporte al desarrollo local.

\section{Conclusiones}

1. Los resultados muestran una escasa colaboración entre los actores estatales y privados del alojamiento turístico, lo cual influye en los niveles de desarrollo turístico del municipio de Santa Clara.

2. La informalidad, la desorganización y el desconocimiento son las principales características de las relaciones entre los actores estatales y privados 
del sector de alojamiento turístico del destino Santa Clara.

3. Hay una evidente correlación entre el nivel de desarrollo turístico del territorio y las características de las relaciones de sus actores.

4. Existe una deficiente gestión de gobierno territorial en función de la cooperación entre los sectores público y privado-individual de alojamiento turístico del municipio y su correspondencia y aporte al desarrollo local.

\section{Fuentes consultadas}

Mintur. (2016). Informe comercial cierre 2016. Delegación territorial del Ministerio de Turismo Villa Clara.

Oficina Nacional de Administración Tributaria. (2016). Registro de Arrendadores del Municipio de Santa Clara 2015. Santa Clara: Autor.

Oficina Nacional de Estadísticas. (2016). Anuario Estadístico de Santa Clara 2015. Recuperado de http://www.one.cu

Organización Mundial del Turismo. (2001). Cooperación entre los sectores público y privado. Para una mayor competitividad del turismo. Madrid: Autor.

Partido Comunista de Cuba (2011). Lineamientos de la Política Económica y Social del Partido y la Revolución. La Habana: Oficina de Publicaciones del Comité Central del Partido Comunista de Cuba.

Perelló, J. L. (2015). El sector no estatal y su papel en el desarrollo del turismo cubano en un escenario de relaciones con Estados Unidos. En Miradas a la economía cubana (pp. 85-91). La Habana: Caminos.

Rodríguez, R. M. y Fernández, J. I. P. (2009). Desarrollo turístico y dinámica relacional. Metodología de análisis para la gestión activa de destinos turísticos. Cuadernos de Turismo, 23, 173-194.

Velasco, M. (2016). Entre el poder y la racionalidad: gobierno del turismo, política turística, planificación turística y gestión pública del turismo. $\mathrm{Pu}$ blic Action and Tourism Policy, 14, 577. 
